\title{
Design optimization of permeable sediment traps for fluvial bed load transport
}

\author{
Anita Roth $^{1, *}$, Mona Jafarnejad ${ }^{1}$, Sebastian Schwindt ${ }^{2}$, and Anton Schleiss ${ }^{1}$ \\ ${ }^{1}$ Laboratory of Hydraulic Constructions (LCH), École Polytechnique Fédérale de Lausanne (EPFL), \\ 1015 Lausanne, Switzerland \\ ${ }^{2}$ Department of Land, Air and Water Resources, UC Davis, 95616 Davis, California, USA
}

\begin{abstract}
Sediment traps are crucial elements for flood protection in mountain rivers with high sediment transport capacity. Existing structures often interrupt the channel connectivity. Ideally, a sediment trap should be permeable for bed load during non-hazardous floods and ensure sediment retention during hazardous discharges. A new sediment trap concept, fulfilling these requirements was recently developed and tested in a laboratory flume. A guiding channel trough the deposition area is combined with a slot check dam having an upstream bar screen with bottom clearance. This study aims to validate the proposed concept with a finer sediment mixture on an experimental set-up. Furthermore, we provide improved recommendations for bar screen design regarding minimal bar spacing and the range of applicable clearance heights. Optimal bar spacing and clearance heights of the bar screen are determined through individual tests of the bar screen with steady discharges and varying sediment supply intensity. The best performing bar screen configuration is subsequently tested in combination with a slot check dam using a flood hydrograph to simulate the influence of quasi-unsteady discharge. The proposed concept corresponds to a combined mechanical-hydraulic control and works well for a large range of grain sizes, if the bar screen is correctly adapted.
\end{abstract}

\section{Introduction}

Alpine rivers can transport large volumes of bed load during a flood event. This increases the danger of flooding downstream [1]. Sediment traps are commonly used protection structures that aim to collect the transported material behind a barrier to avoid damages in populated downstream reaches. Two distinct control mechanisms may trigger sediment retention: mechanical and hydraulic [2]. Mechanical control describes direct clogging of small openings in a flow barrier. This is directly related to the grain sizes of the transported sediment which have to be estimated. Hydraulic deposition control describes deposition caused by an obstacle to the flow which creates a calm water area with a lower energy slope. A problem of hydraulic control mechanisms is that previously deposited sediment may be flushed out during the flood [2]. Additionally, to the uncertainties associated with each control mechanism, structures currently in use often interrupt the morphological continuity

\footnotetext{
* Corresponding author: anita.roth@alumni.epfl.ch
} 
of rivers because they retain most of the transported sediment, irrespective of the discharge. This may lead to morphological depletion and channel erosion downstream [3]. [4] recently developed a concept which enables sediment passage up to a target discharge that is nonhazardous to downstream reaches. The concept combines a mechanical and a hydraulic deposition control mechanism to incorporate both reliability of sediment retention and transport continuity during small floods. The main elements of the proposed concept are: (1) a guiding channel across the deposition area to control the flow conditions upstream of the barrier; (2) a bar screen, which mechanically controls bed load retention but enables the uninterrupted passage of non-hazardous discharges; and (3) an adjacent downstream slot check dam imposing hydraulic deposition control of bed load retention. The common features of a permeable sediment trap according to $[4,2,5]$ are outlined in Fig. 1. The combination of these control elements enables the desired permeability while it mitigates the risk associated with each control mechanism. The risk of self-flushing during floods is mitigated by mechanical clogging of the bar screen. In turn, the clogging probability of the bar screen is increased by the backwater of the hydraulic control. The bank full discharge of the guiding channel is equal to the target discharge for triggering retention.

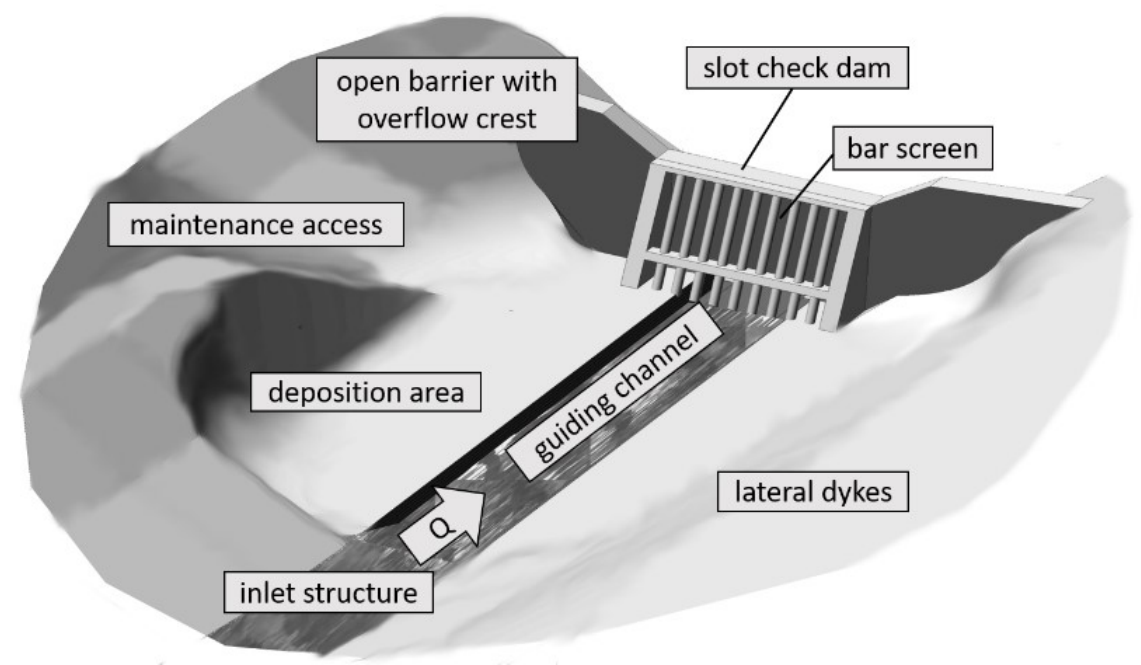

Fig. 1. Concept of a permeable sediment trap after [4].

So far, this concept has been tested with a coarse grain supply mixture on an experimental setup $[6,7,4]$. We revalidate the design with a finer grain supply mixture and provide further testing on the optimal bar screen design parameters. If the bar screen is well adapted, the combination of bar screen, guiding channel and slot check dam provides safe retention and permeability for non-hazardous discharges. However, for fine grain sizes, the bar spacing and clearance height need to be increased to avoid clogging caused by a hydraulic effect of the bar screen.

\section{Methodology}

\subsection{Experimental setup}

The model consists of a $2.5 \mathrm{~m}$ long adaptation reach that serves for sediment and water mixing and a subsequent $3.0 \mathrm{~m}$ long observation reach. The observation reach includes the guiding channel and the deposition area, which has a length of $1.60 \mathrm{~m}$ and a width of $1.20 \mathrm{~m}$. 
The trapezoidal guiding channel (Fig. 2) has a bank full discharge of $5.5 \mathrm{l} / \mathrm{s}$, corresponding to a flow depth of $3.2 \mathrm{~cm}$. It has a bank inclination of $m=2.25$, a bottom width $w=0.11 \mathrm{~m}$ and a longitudinal slope $S_{0}$ of $6 \%$. Both the sediments and the pump discharge enter the model at the start of the adaptation reach. At the outlet of the model, the outflowing sediment is collected and weighted in a filter basket. Additionally, the deposition area and the barrier are recorded by a camera. The supplied sediment has the following characteristics: $D_{30}=5.6 \mathrm{~mm} ; \quad D_{50}=6.4 \mathrm{~mm} ; D_{90}=8.7 \mathrm{~mm} ; D_{84}=8.0 \mathrm{~mm}$ and $\sigma=1.26$, where $\sigma=0.5\left(D_{84} / D_{50}+D_{50} / D_{16}\right)$. In line with [8] $D_{84}$ is considered the representative grain size of the transported bed load. The coarser grain size mixture used previously was characterized by $D_{30}=8.4 \mathrm{~mm} ; D_{50}=9.7 \mathrm{~mm} ; D_{90}=14.8 \mathrm{~mm} ; D_{84}=13.7 \mathrm{~mm}$ and $\sigma=1.37$ [9].

Fig. 2 shows the geometry of the bar screen and the slot check dam. The bar screen is characterized by the spacing between the bars $b_{\mathrm{i}}$, and the clearance height $f_{\mathrm{m}} \cdot D_{84}$ between the bottom of the guiding channel and the bars. For the combined control, the slot check dam is placed directly after the bar screen (for detailed descriptions see [4]).
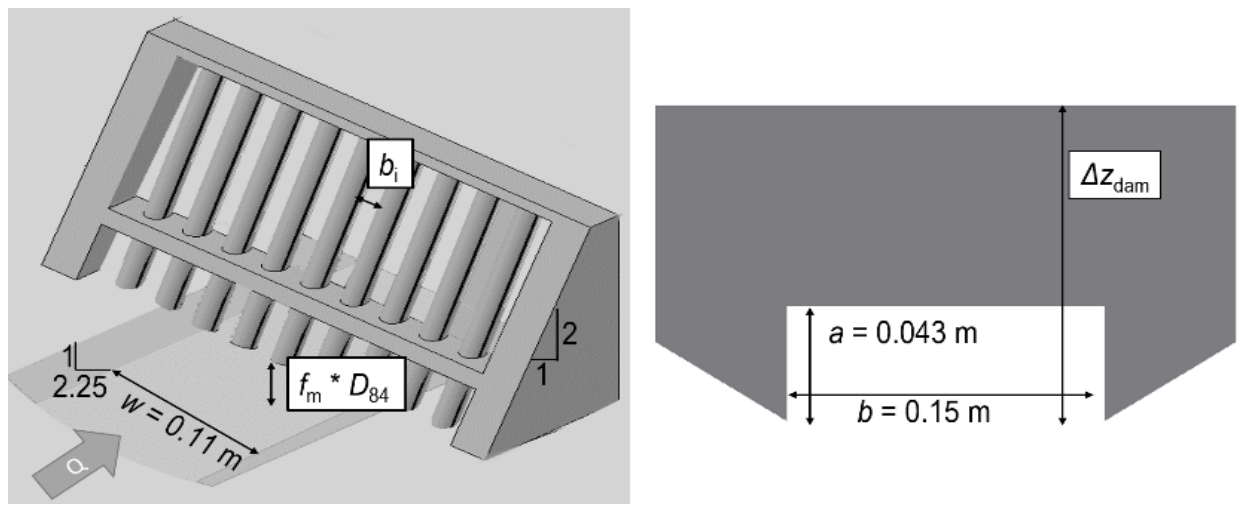

Fig. 2. Geometry of the guiding channel, bar screen and slot check dam.

\subsection{Experimental procedure}

The bed load transport capacity $Q_{\mathrm{b}, \max }$ describes the maximum amount of bed load that may be transported for a given discharge. It is determined by increasing the sediment supply for a given discharge until a maximum value is reached. The maximum value corresponds to the highest sediment transport rate where no deposition occurs in the channel. This procedure is performed in the non-constricted guiding channel, to obtain reference values $Q_{\mathrm{b}, \max , 1}$. Subsequently, the bed load transport capacity $Q_{\mathrm{b}, \mathrm{max}, \mathrm{j}}$ is tested with different bar screen configurations $\mathrm{j}$. The discharges range from $3.5 \mathrm{l} / \mathrm{s}$ to $7.2 \mathrm{l} / \mathrm{s}$. The clogging probability of a bar screen is estimated using the time to clogging $t_{\mathrm{c}}$ which is defined as the time from the first grain passing the bar screen to the first grain becoming entangled. $t_{\mathrm{c}}<10 \mathrm{~s}$ is considered quick and indicates a high clogging probability. It is recorded using a stopwatch and a camera.

To test the correct functioning of the combined control consisting of the bar screen and a slot check dam, a generic flood hydrograph (quasi unsteady flow conditions) is used. Its initial discharge corresponds to the bank full discharge of the guiding channel. Each discharge and sediment supply is constant for 3 to 4 minutes with subsequent increases that represent the next flood stage. The peak discharge starts at 19 min and the total duration corresponds to $55 \mathrm{~min}$. (see [4] for details). The combined barrier with hydraulic-mechanical 
control was tested twice and the outflowing bed load $Q_{\mathrm{b}, \text { out }}$ was measured minute-wise (every two minutes).

\section{Parameters}

The reduction in the bed load transport capacity caused by the flow constriction is expressed by the reduction rate $\theta$. It represents the ratio of the maximum bed load transport capacity $Q_{\mathrm{b}, \mathrm{max}, \mathrm{j}}$ of each bar screen configuration $\mathrm{j}$ and the maximum bed load transport capacity of the non-constricted flow $Q_{\mathrm{b}, \max , 1}$.

$$
\theta=\frac{Q_{\mathrm{b}, \max , \mathrm{j}}}{Q_{\mathrm{b}, \max , 1}}=f(j)
$$

\section{Results}

\subsection{Bar spacing}

The target discharge for sediment retention is $5.5 \mathrm{l} / \mathrm{s}$, which corresponds to the bank full discharge of the guiding channel. For smaller discharges, the reduction in the bed load transport capacity should be small, corresponding to large values of $\theta$ while for larger discharges, an immediate clogging of the bar screen is desirable. Fig. 3 shows the bed load transport capacity reduction rate $\theta$ as a function of the discharge $Q$ for different bar spacings $b_{\mathrm{i}}$ and clearance heights $f_{\mathrm{m}} \cdot D_{84}$.

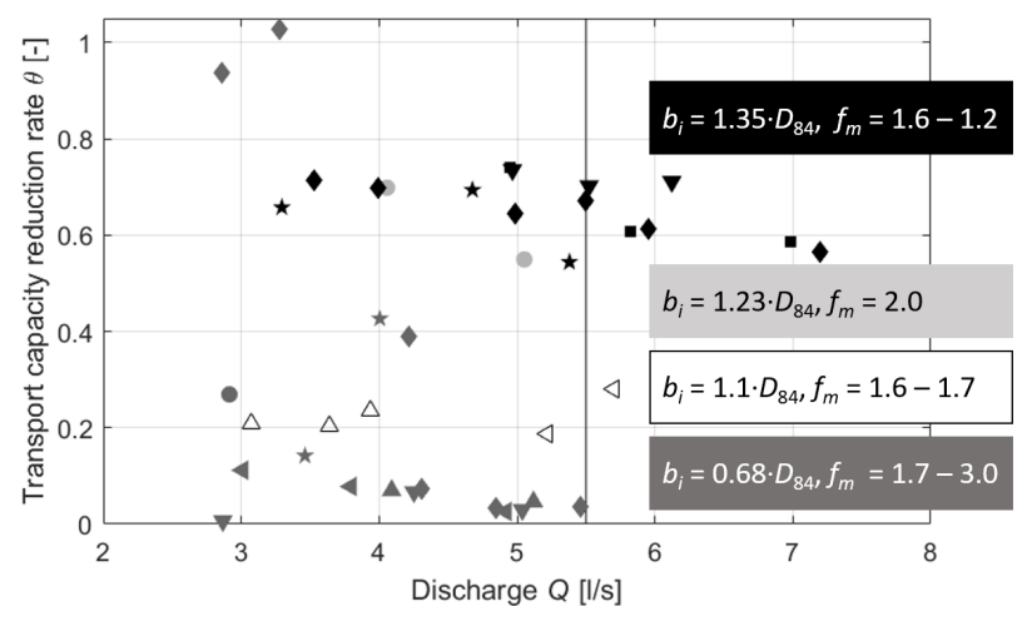

Fig. 3. Bed load transport capacity reduction rate $\theta$ as a function of the discharge $Q$ for different bar spacings $b_{\mathrm{i}}$ (color) and varying clearance heights $f_{\mathrm{m}} \cdot D_{84}$ (symbol).

Bar spacings $b_{\mathrm{i}} \leq 1.1 \cdot D_{84}$ cause fast clogging and large reductions in the transport capacity, irrespective of the discharge and clearance height. They therefore do not provide the desired permeability. Both $b_{\mathrm{i}}=1.23 \cdot D_{84}$ and $b_{\mathrm{i}}=1.35 \cdot D_{84}$ show a small impact on transport capacity for $Q<5.5 \mathrm{l} / \mathrm{s}$ corresponding to $\theta \approx 0.75$. In the constricted flume, the reduction of the transport capacity increases with increasing discharge. Thus, along with a fast clogging of the bar screen at $Q>5.5 \mathrm{l} / \mathrm{s}$, safe retention is provided. 
Both $b_{\mathrm{i}}=1.23 \cdot D_{84}$ and $b_{\mathrm{i}}=1.35 \cdot D_{84}$ safely retain sediment at large discharges. Thus, to maximize permeability for non-hazardous discharges, a bar spacing of $b_{\mathrm{i}}=1.35 \cdot D_{84}$ is retained for the following analysis.

\subsection{Clearance height}

To determine the optimal clearance height below the bar screen, different bar screens with the chosen bar spacing of $b_{\mathrm{i}}=1.35 \cdot D_{84}$ are compared. Fig. 4 shows the transport capacity reduction rate $\theta$ for the tested clearance heights. The time to clogging $t_{\mathrm{c}}$ is considered to evaluate the clogging probability. A bar screen with $f_{\mathrm{m}}=1.98$ has a time to clogging $t_{\mathrm{c}} \approx 30 \mathrm{~s}$, which is long in the framework of the laboratory flume. Furthermore, previously deposited sediment is flushed out, which outweighs the purpose of retention. Clearance heights of $f_{\mathrm{m}}=$ $1.59-1.85 \cdot D_{84}$ show times-to-clogging of $t_{\mathrm{c}}<10 \mathrm{~s}$ for $Q>5.5 \mathrm{l} / \mathrm{s}$. This indicates a high clogging probability. To maximize permeability at $Q<5.5 \mathrm{l} / \mathrm{s}$ while ensuring retention at $Q>$ $5.5 \mathrm{l} / \mathrm{s}$, a range of $f_{\mathrm{m}}=1.73-1.85$ is determined as being suitable. Both show larger values of $\theta$ for small discharges and a significant decrease at the target discharge for retention of $5.5 \mathrm{l} / \mathrm{s}$. To maximize permeability, a clearance height of $1.85 \cdot D_{84}$ is retained for the following analysis.

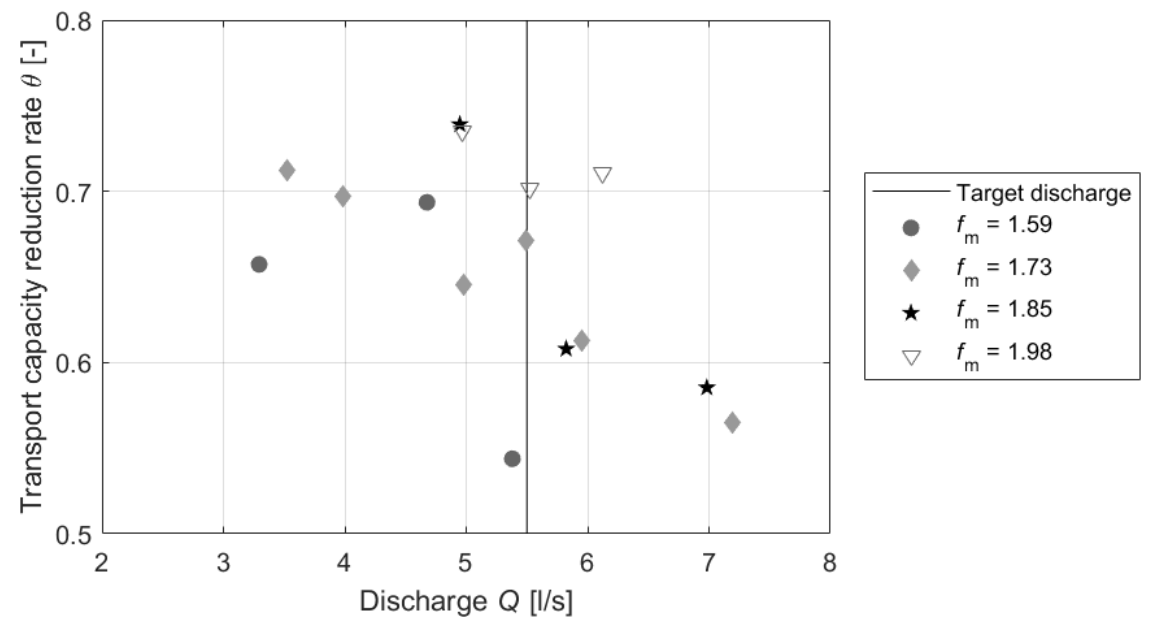

Fig. 4. Transport capacity reduction rate $\theta$ as a function of the discharge for a bar spacing of $b_{\mathrm{i}}=1.35 \cdot D_{84}$ and different clearance heights $f_{\mathrm{m}} \cdot D_{84}$.

\subsection{Combined control barrier}

The previously determined optimal bar screen with $b_{\mathrm{i}}=1.35 \cdot D_{84}$ and $f_{\mathrm{m}}=1.85$ is tested in combination with the slot check dam using a generic flood hydrograph. The initial discharge corresponds to the target discharge of 5.5 1/s. Fig. 5 shows the development of the outflowing bed load over time. The behavior of the fine sediment mixture is similar to the results previously obtained for coarse sediment [4], if the bar screen is correctly adapted: The barrier is permeable for bed load at $5.5 \mathrm{l} / \mathrm{s}$. The first increase in the discharge and sediment supply after 3 min leads to the immediate clogging of the bar screen and the outflowing bed load rate decreases to almost zero. Subsequently, the barrier is backfilled with little sediment outflow, until the deposit height reaches the height of the barrier after $16 \mathrm{~min}$ and the outflowing bed load approximately corresponds to the sediment supply. 


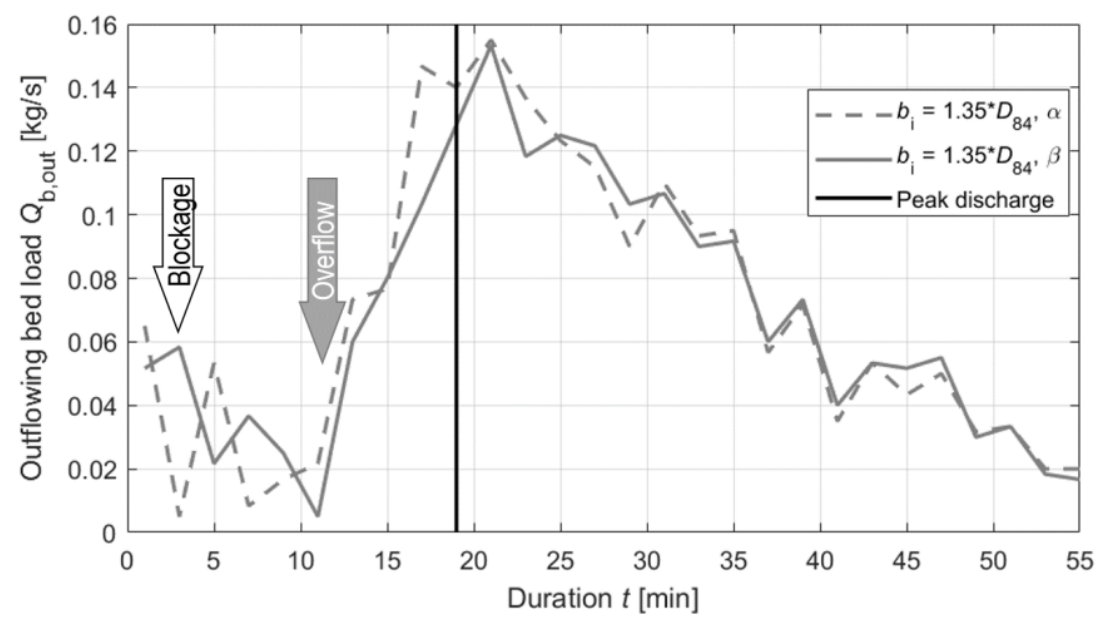

Fig. 5. Development of the outflowing bed load $Q_{\mathrm{b}, \text { out }}$ during a simulated flood event for repetitive runs $\alpha$ and 6 .

\section{Discussion}

The previously defined parameter values for the bar screen design: bar spacing $b_{\mathrm{i}}=D_{84}$ and clearance height $f_{\mathrm{m}} \cdot D_{84}$ where $f_{\mathrm{m}}=1.75$ [7] for a coarse sediment mixture, are coherent with the values found here. However, for finer sediment and therefore smaller $D_{84}$, bar spacings of $b_{\mathrm{i}}<1.23 \cdot D_{84}$ may cause sediment retention when the discharge and the bed load transport are small (corresponding to non-hazardous floods). The retention is attributed to hydraulic effects of the bar screen and needs to be considered when choosing the bar spacing. Values of $b_{\mathrm{i}}=1.35 \cdot D_{84}$ still provide safe retention but the unwanted retention at smaller discharges and related bed load is avoided. A larger bar spacing is not recommended as the clogging probability is too low. Hence, the optimum bar spacing corresponds to a range of $b_{\mathrm{i}}=1$ $1.35 \cdot D_{84}$. Depending on the uncertainty in estimating $D_{84}$ a choice at the lower end of the proposed range may be suitable to enhance sediment retention. The clearance height of $f_{\mathrm{m}} \cdot D_{84}$ was previously found to be optimal at $f_{\mathrm{m}}=1.75$. The new results indicate that $f_{\mathrm{m}}=1.85$, still enables fast clogging but improves the sediment transfer for smaller discharges.

\section{Conclusions}

The sediment grain size influences the design of the clearance height and bar spacing of bar screens of sediment traps in mountain river-like channels. Such a bar screen mechanically clogs during hazardous floods when grains entangle between individual bars. However, a bar screen imposes an additional, undesired hydraulic control of sediment retention when the underlying grain size for the clearance height and bar spacing is small. This study shows that a slight increase of previously defined design parameters, based on a coarse grain size distribution, is advantageous for sediment transfer up to small floods but still enables the safe retention of larger, hazardous floods. This goal is achieved for fine to coarse grain size distribution when the horizontal bar spacing corresponds to $1-1.35$ times the $D_{84}$ of the bed load and when the clearance height under the bar screen corresponds to $1.73-1.85$ times the $D_{84}$ of the transported bed load. 


\section{References}

[1] K. Bergmeister, J. Suda, J. Hübl, F. Rudolf-Miklau, Schutzbauwerke gegen Wildbachgefahren: Grundlagen, Entwurf und Bemessung, Beispiele [Alpine flood protection: Planning basics, Design and Dimensioning, Examples] (Ernst \& Sohn, Berlin, Germany, 2009)

[2] G. Piton, A. Recking, Journal of Hydraulic Engineering 142, 04015045 (2016)

[3] G.P. Williams, M.G. Wolman, in Geological Survey Professional (U.S. Government,Washington, DC, 1984), Paper 1286

[4] S. Schwindt, M.J. Franca, A. Reffo, A.J. Schleiss, Natural Hazards and Earth System Sciences Discussions 18, 647-668 (2018)

[5] F. Zollinger, Die verschiedenen Funktionen von Geschieberückhaltebauwerken [The different functions of debris retention dams], in Proceedings of INTERPRAEVENT (International Research Society Interpraevent, Klagenfurt, Austria, 1984), pp. 147-160

[6] S. Schwindt, M.J. Franca, A.J. Schleiss, Journal of Hydraulic Engineering 143, 04017052 (2017)

[7] S. Schwindt, M.J. Franca, G. De Cesare, A.J. Schleiss, Geomorphology 295, 467-479 (2017)

[8] V. D’Agostino, in Check dams, morphological adjustments and erosion control in torrential streams, edited by C. Garcia, M.A. Lenzi (Nova Science, 2013), chap. 9, pp. $185-210$

[9] S. Schwindt, Hydro-morphological processes through permeable sediment traps, Communication LCH 71 (LCH, Lausanne, Switzerland, 2017) 